\title{
Quantifying the emergy flow of an urban complex and the ecological services of a satellite town: a case study of Zengcheng, China
}

\author{
Junying Zhang a, b, Yutao Wang a, c, *, Chengdong Wang a , Renqing Wang a , Feng Li ${ }^{\text {b, ** }}$ \\ ${ }^{a}$ Institute of Ecology and Biodiversity, School of Biological Sciences, Jinan 250100, Shandong University, PR China \\ b State Key Laboratory of Urban and Regional Ecology, Research Center for Eco-Environmental Sciences, Chinese Academy of Sciences, 18 Shuangqing Road, \\ Haidian District, Beijing 100085, PR China \\ ${ }^{c}$ Department of Industrial System and Engineering, University of Tennessee, Knoxville 37996, USA
}

\section{A R T I C L E I N F O}

\section{Article history:}

Received 24 November 2015

Received in revised form

10 February 2016

Accepted 11 February 2016

Available online 19 February 2016

\section{Keywords:}

Emergy analysis

Emergy indices

Sustainability

Ecological services

Zengcheng

\begin{abstract}
A B S T R A C T
In recent years, the sustainability of many metropolitan areas has been degraded due to rapid economic development. Zengcheng, as a satellite city of Guangzhou, has been developed as a demonstration area for improving regional urban sustainability and expanding the overall ecological capacity of Guangzhou. In this paper, an integrated evaluation based on emergy synthesis theory was conducted to examine whether Zengcheng can fulfill its role in providing ecological services and improving regional sustainability. Based on emergy indices, we assessed the sustainability of the social, economic, and ecological subsystems of Zengcheng. The results showed that the total emergy used (U), the emergy used per person (Ucap) and the empower density (ED) of Zengcheng were all at a low level compared to a selection of developed cities. However, the Ucap and the ED were higher than the national average. The emergy investment ratio (EMR) of Zengcheng was lower than all the selected areas in this study, suggesting that the development of Zengcheng is mainly reliant on the consumption of local resources. The Emergy Sustainable Index (ESI) of Zengcheng is 0.72 which is lower than many highly developed areas. Furthermore, three categories of ecological services of Zengcheng were also evaluated based on emergy. The results show that the total emergy-dollar value of ecosystem services and the ecological services empower density (ESED) in Zengcheng were $\$ 6.17 \mathrm{E}+09$ and $1.20 \mathrm{E}+13 \mathrm{sej} / \mathrm{m}^{2}$, respectively. This indicates that Zengcheng can provide substantial ecological services and increase the overall ecological capacity of the Guangzhou region.
\end{abstract}

(c) 2016 Elsevier Ltd. All rights reserved.

\section{Introduction}

Since the middle of the last century, a few extremely large metropolitan areas have emerged around the world, for instance, the northeastern seaboard of the United States (Gottmann, 1964). A metropolitan area normally consists of one or two core mega cities and a number of surrounding small and medium-sized cities which play difference roles in the complex. As connection nodes for central cities and peripheral areas, the small and medium-sized cities play an important role in realizing regional economic growth through participating in economic cycles and division. The

\footnotetext{
* Corresponding author. Post address: Institute of Ecology and Biodiversity, School of Biological Sciences, Shandong University, Jinan 250100, PR China. Tel.: +86137 9100 0956; fax: +86 53188363573 .

** Corresponding author. Tel.: +86 1364123 1818; fax: +86 1062849103 .

E-mail addresses: yutaowang@sdu.edu.cn (Y. Wang), lifeng@rcees.ac.cn (F. Li).
}

big cities can also transfer some of their functions to neighboring small and medium-sized cities to relieve the pressure brought by the growing population, heavy traffic, and deteriorated environment (Fahmi et al., 2014).

China has been on a track of fast urbanization since the 1980s, and a few mega cities such as Beijing, Shanghai, and Guangzhou have been developed. The rapid urbanization has improved the living standard of residents and the mega cities have advantages such as better opportunities for education, employment, and medical care. However, the rapid urbanization also creates a series of serious problems which constrain the sustainability of China's cities. A growing amount of ecological land has been converted into construction land with significant losses in ecological services (Zheng et al., 2007). There has been a significant amount of research in the field of urban land use change. Gong et al. (2012) used a matter-element model to evaluate land suitability for development and they pointed out that land that was unsuitable for development 
makes up a large proportion of the total land area at present because of the high intensity of land development. Future land use changes in the Bindura district of Zimbabwe were simulated with a Markov-cellular automata model and the results showed that severe land degradation will ensue unless some effective sustainable development measures are adopted (Kamusoko et al., 2009). The problem of land use conversion is exacerbated by the increased demand for agricultural land that results from a growing population (Dolman and Verhagen, 2003). The changes in land use have also resulted in environmental stress, such as shortages of water, loss of biodiversity, and increased $\mathrm{CO}_{2}$ content in the atmosphere (Dolman and Verhagen, 2003). Another issue is that fossil fuel has been extensively used by different sectors in the Yellow River Delta which has produced thousands of tons of emissions and has frequently caused severe smog over a large area of China (Sun et al., 2014). Traffic congestion in mega cities, which is a major source of air pollution, has become increasingly severe (Molina and Molina, 2004). All these issues, which greatly threaten the sustainability of Chinese cities, should be urgently addressed. As previously mentioned, the development of small and medium-sized cities may help to release the increasingly intensive pressures of big cities. Cohen (2006) pointed out that the rapid urban growth of developing countries has seriously outstripped the capacity of most cities to provide adequate services for their citizens. Rumbach (2016) reported that a transition from mega cities to small and medium-sized cities can improve the local capacity for effectively facing many challenging issues, including the management of hazards, disasters, and the effects of global climate change. In response to these challenges, speeding up the development of small and medium-sized cities has been regarded as one important approach to fulfill China's so called new urbanization strategy (NDRC, 2014). Although the government has been actively promoting the development of small and medium-sized cities in China, research is still required to better understand the role of small and medium-sized cities in improving regional sustainability as well as the value of ecological services that can be provided by those small and medium-sized cities that are developed for the purpose of enlarging regional ecological capacity. To this end, we chose Zengcheng, a satellite city of Guangzhou, as a study city for our research. We selected Zengcheng because it has been developed as a demonstration area for increasing local ecological capacity and improving urban sustainability. One of the important roles of Zengcheng is to provide ecological services and expand the overall ecological capacity of this metropolitan region. Zengcheng is also designed to develop its economy to mitigate the economic and population pressures of Guangzhou. Additional details about Zengcheng will be given in the following section. A comprehensive evaluation of Zengcheng is needed to provide a clear understanding of whether Zengcheng can fulfill its mission of simultaneously developing the economy and providing ecological services. The evaluation will also determine the level of regional sustainability improvement that results from increases in these ecological services. The outcome of this study will hopefully also improve city planning and governance for similar small and medium-sized cities in China.

In this paper, we used emergy analysis to evaluate the sustainability of Zengcheng via holistic considerations of its economy, society, and ecosystem. Emergy analysis, which can combine the natural subsystem with the social economic system, has proved to be an effective method to evaluate systems, and it also has been in utilized in a wide variety of applications (Jiang et al., 2009; Liu et al., 2014). At the national scale, many countries have been studied based on emergy analysis. Ulgiati et al. (1994) used emergy to assess the environmental loading and sustainability of Italy. Jiang et al. (2008) evaluated the sustainability of Chinese economy based on emergy synthesis theory. This method has also been widely used to study developed cities. Lei et al. (2008) adopted the emergy analysis method to evaluate the sustainability of Macao. Ascione et al. (2009) used emergy synthesis to quantify the complexity of Rome. Beijing and Montreal were also studied with this method (Jiang et al., 2009; Vega-Azamar et al., 2013; Zhang et al., 2011). Zhang et al. (2009) compared three typical mega cities based on emergy analysis. In recent years, emergy analysis has also been employed to research the sustainability of industrial parks. He et al. (2017) identified the balance between natural and socioeconomic factors within an industrial park. Fang et al. (2015) established a carbon emissions accounting framework for low-carbon industrial parks based on emergy. However, there is a paucity of studies on the ecological services provided by urban ecosystems that utilize emergy methods. Ecosystems can provide essential ecological services to human economies and societies, and these services have received increasing attention from academics and the general population (Costanza et al., 1997; Mellino et al., 2015). However, the value of ecological services will be more easily understood by different stakeholders if they are measured in monetary units. In this paper, we apply a quantitative analytic framework based upon emergy analysis to evaluate the sustainability of Zengcheng and we then evaluated the value of the ecological services provided by Zengcheng to better understand the role of this city in improving regional urban sustainability.

\section{Materials and methodology}

\subsection{Case study area}

Zengcheng, a satellite city of Guangzhou in China, is characterized by abundant natural resources and different industries. It is famous for its production of litchi, denim jeans, and automobiles as well as a demonstration area for tourism. Zengcheng consists of 4 Sub-districts and 7 towns with a total area of $1616.47 \mathrm{~km}^{2}$ (OWZM, 2015). Zengcheng has an abundance of natural resources based on the multitude of mountains and rivers. One of the most famous rivers is the Zengjiang River, which runs through Zhengcheng from north to south and then exits into the Pearl River. The Zengjiang River extends approximately $66 \mathrm{~km}$ within the area of Zengcheng, and the basin area is 971 square kilometers, which accounts for 53 percent of the total city area (ZMSB, 2008).

As a hotspot region of Guangzhou's urban eastward expansion, Zengcheng has been earnestly implementing scientific concepts of development and actively exploring the economic development model. In recent years, Zengcheng has established three major function zones. The north area was classified as the restricted development area, and economic activities which may affect the ecological environment were strictly controlled in this area. This functional area is focused on building the bases for tourism via developing ecological tourism, the conference industry, and urban agriculture as well as, building the area into an internationally recognized country park. The central area was designated as the optimized development area. As the residential zone of Zengcheng, the development purpose of this area was to "promote urban services and culture". This entails prioritizing the construction of buildings related to culture and urban services. In order to achieve the sustainable development, the industrial structure will be modified and tighter industry performance standards will be implemented in this area. The southern area was defined as the major development area. In this area, the policy was mainly guided by investing in the construction of infrastructure, the industrial park, and the automobile industry. Additional land for construction purposes will be supplied and the development of the industry group will be supported in this zone (ZPB, 2007) (Fig. 1). 


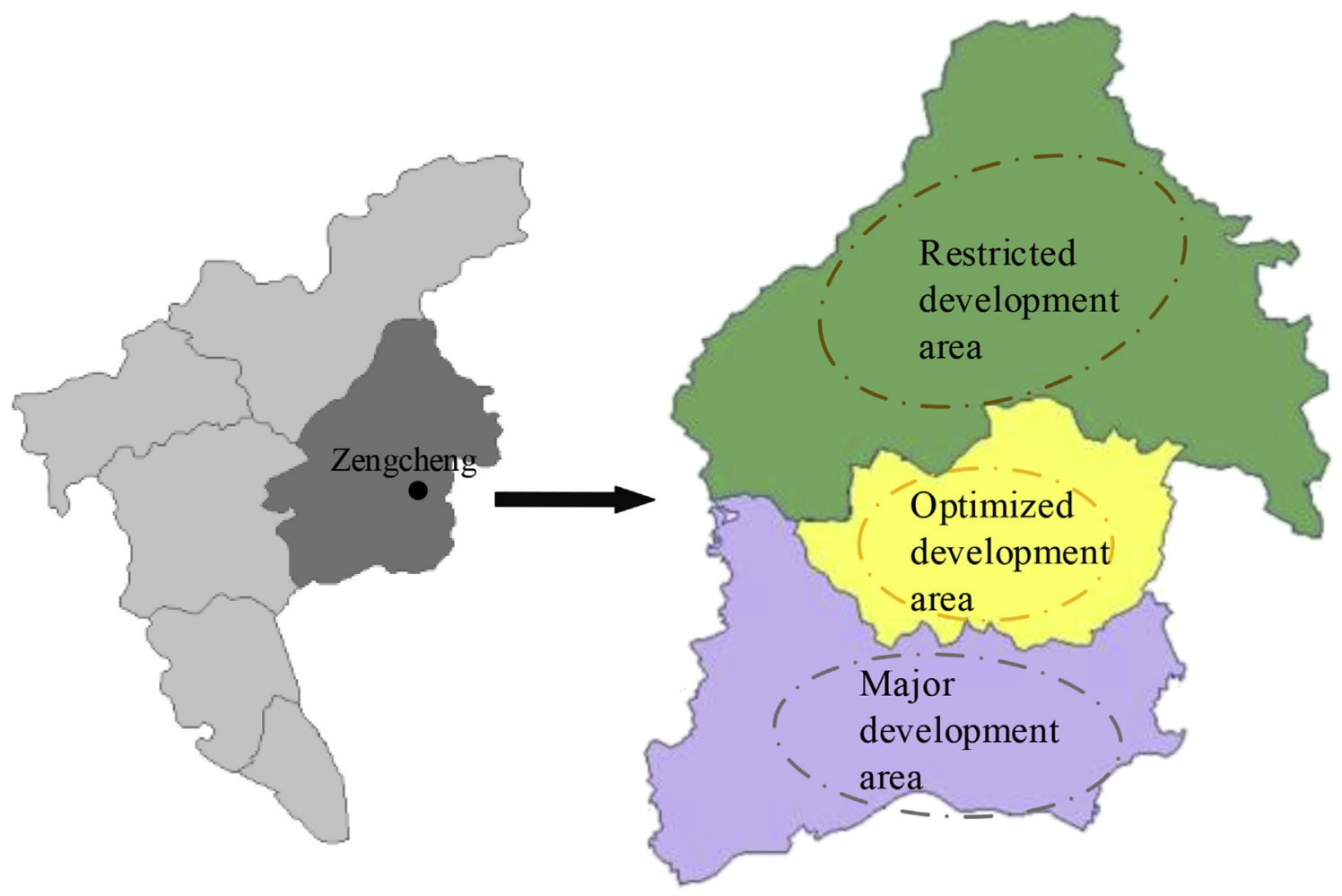

Fig. 1. The location of Zengcheng in Guangzhou and the three major functional zones of Zengcheng.

Zengcheng has experienced a rapid development of its economy in the last few years, and this development has made significant improvements in many respects. However, several problems were also produced at the same time, such as the degradation of sustainability in this district and the reduction in ecological services (Gong et al., 2012; Zheng et al., 2007). These problems present a significant challenge.

\subsection{Emergy flows across the district}

Emergy is defined as the total amount of available energy that is directly or indirectly needed to make a product or service (Odum, 1996). Since many types of energy are ultimately derived from solar energy, the solar emergy joule can be utilized as the benchmark metric to quantify various kinds of energy. Emergy can integrate various forms of materials and energy in a uniform unit by means of suitable transformities. The transformity refers to the energy of one type required per unit of another (Odum, 1988). Odum and his colleagues calculated values of transformities, so the emergy for different forms of services, sources, and productions can be derived. The baseline of this study refers to $15.83 \mathrm{E}+24 \mathrm{sej} / \mathrm{yr}$. Emergy analysis provides an integrated evaluation of the ecological system and economic system, and the method allows for the assessment of a city's sustainability (Liu et al., 2013; Zhang et al., 2011).

The overall strategic development plan of Zengcheng was proposed in 2007 and approved by the People's Congress of Zengcheng in 2008. We collected the geographic and social economic data for Zengcheng in 2008. We then calculated environmental and economic flows within and outside the social-economic-natural complex of this district. Finally, we evaluated the sustainability and the value of ecological services value in this city against the background of the implemented strategic plan. The primary data used in this study was obtained from local statistical documents, published reports, and related literature (ZWSB, 2008; GMSB, 2008).

The emergy diagram of Zengcheng is shown in Fig. 2, with the major components and flows involved. Some typical indicators were also calculated and compared with those of selected cities or regions.

\subsection{Value of ecological services based on the emergy analysis method}

There are 4 categories of ecological services based on the Millennium Ecosystem Assessment (MEAP, 2005): provisioning services, regulating services, supporting services and cultural services. We only considered 3 categories of ecological services and excluded the provisioning services in order to avoid duplication in accounting. The ecological services value of Zengcheng was calculated based on data 2008. To simplify computation, all forest areas were treated as broad-leaf forest.

\subsubsection{Regulating services}

In this paper, regulating services are considered to consist of greenhouse gas regulation and pollution treatment. Greenhouse gas regulation consists of fixed carbon dioxide and released oxygen, and pollution treatment mainly refers to the absorption of sulfur dioxide and the retardation of dust. The computation formulas are as follows:

$E_{\mathrm{CO}_{2}}=1.63 \times \mathrm{NPP} \times \mathrm{T}_{\mathrm{CO}_{2}}$

$E_{O_{2}}=1.99 \times N P P \times T_{O_{2}}$

where $E_{\mathrm{CO}_{2}}$ is the emergy of fixed carbon dioxide, sej; $E_{\mathrm{O}_{2}}$ is the emergy of released oxygen, sej; NPP is the net primary production, $\mathrm{g} \mathrm{C} / \mathrm{yr} ; 1.63$ is the amount of fixed carbon dioxide needed to 


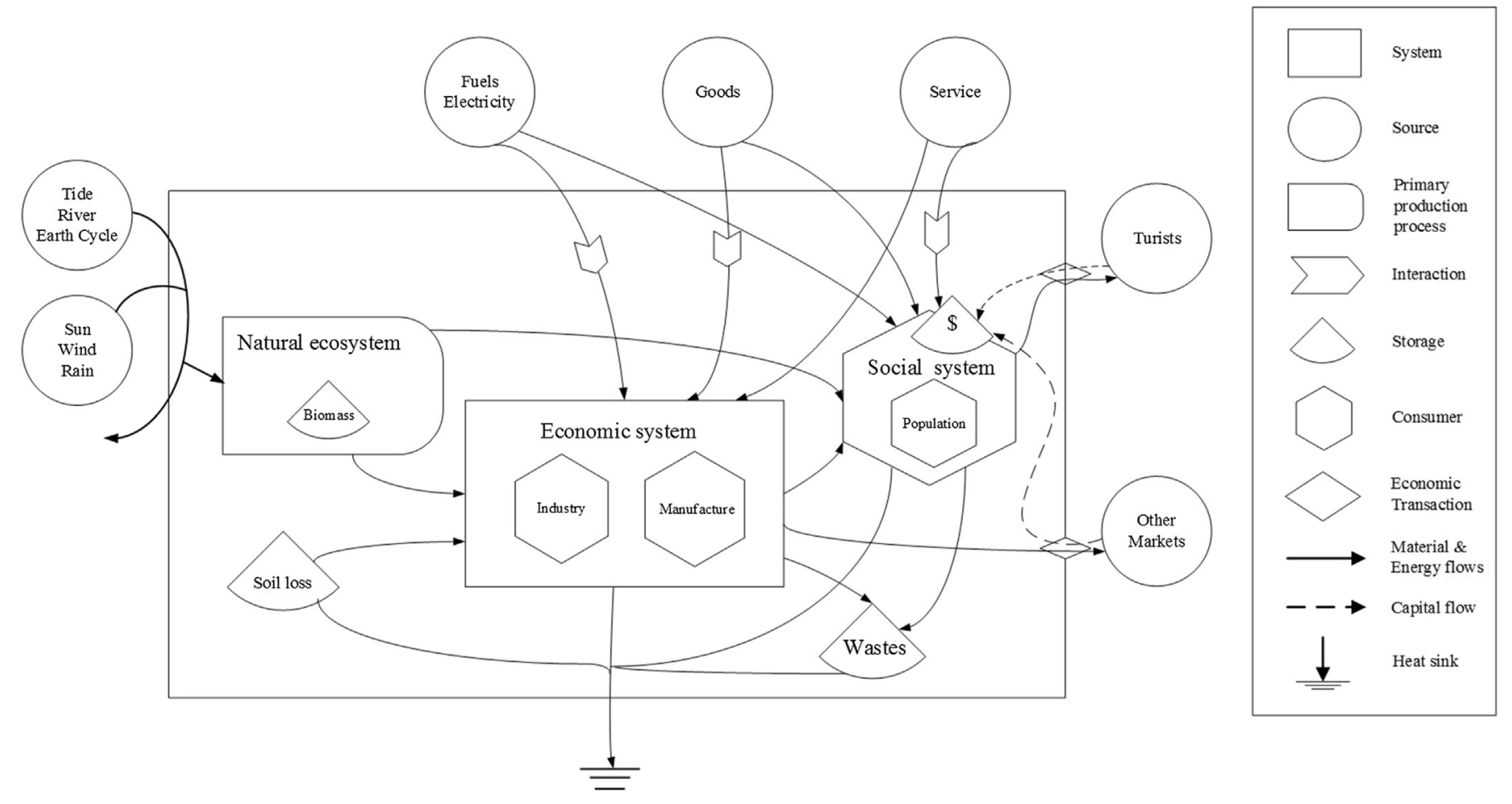

Fig. 2. Emergy diagram of Zengcheng.

produce $1 \mathrm{~g}$ of dry matter, 1.19 is the amount of released oxygen in the production of $1 \mathrm{~g}$ of dry matter; and $\mathrm{T}$ is the transformity of NPP, sej/g.

$E_{i}=S \times u_{i} \times T_{i}$

where $E_{\mathrm{i}}$ is the emergy of absorbed sulfur dioxide or block dust, sej; $\mathrm{S}$ is the forest area, $\mathrm{m} 2$; and $\mathrm{u}_{\mathrm{i}}$ is the ability of the environment to absorb pollutants, $\mathrm{g} / \mathrm{hm}^{2}$. Since the forest was treated as a broadleaf forest in this study, the ability to absorb sulfur dioxide is $8.87 \times 10^{4} \mathrm{~g} / \mathrm{hm}^{2}$, and the capacity to mitigate dust is $1.01 \times 10^{7} \mathrm{~g} /$ $\mathrm{hm}^{2}$. T is the transformity of pollution treatment, sej/g.

\subsubsection{Supporting services}

Supporting services mainly refer to water resource conservation, soil and water conservation, and biodiversity protection. The computation formulas are as follows:

$E=W \times \rho \times G \times T$

$W=(P-E) \times S$

Where $\mathrm{E}$ is the emergy of water resource conservation, sej; $\mathrm{W}$ is the amount of water resource conservation, $\mathrm{m}^{3} ; \rho$ is the density of rain, $10^{3} \mathrm{~kg} / \mathrm{m}^{3} ; \mathrm{G}$ is the Gibbs free energy of water, $4.94 \times 10^{6} \mathrm{~J} / \mathrm{g} ; \mathrm{T}$ is the transformity of water resource conservation, sej/g; $\mathrm{P}$ is the average annual rainfall, $\mathrm{m}$; $\mathrm{E}$ is the average annual evaporation, $\mathrm{m}$; and $\mathrm{S}$ is the forest area, $\mathrm{m}^{2}$.

$E=Q \times u \times T$

$Q=Q_{1}-Q_{2}=d \times \frac{S}{0.051}-\mathrm{d} \times S$

where $E$ is the emergy of soil and water conservation, sej; $Q$ is the amount of soil and water conservation, $g$; $u$ is the topsoil energy conversion ratio, with the average value of subtropical topsoil calorific in China at $19.42 \mathrm{~kJ} / \mathrm{g}$ (Guan et al., 2005); T is the transformity of soil and water conservation, sej/j; $Q_{1}$ is the amount of potential soil erosion, $Q_{2}$ is the amount of real soil erosion; $d$ is the real soil erosion modulus, as the real soil erosion in forest covered area is only $5.1 \%$ of the potential soil erosion; and $S$ is the forest area, $\mathrm{m}^{2}$.

\subsubsection{Cultural services}

The value of cultural services has many aspects, which includes the tangible physical value and the intangible value. In view of data availability, we took ecological tourism revenues as raw data and transformed the revenues into dollars based on the Yuan and the dollar conversion rate.

\section{Results}

\subsection{Emergy-based accounting of Zengcheng in 2008}

Five types of resources associated with the social-economicnatural system are listed in Table 1: renewable resources, renewable production, nonrenewable resources and their products, currency flow, and waste flow. The energy values were multiplied by emergy transformity parameters and then converted into emergy values. Finally, the aggregate emergy flows were calculated and listed in Table 2.

The renewable resources include free renewable resources and indigenous renewable production, and the emergy of the renewable flow was $3.68 \mathrm{E}+22$ sej. Since some of the listed renewable resources (solar, rain, wind and river) are all caused by the same climatic and geophysical effects, only the largest renewable flow was selected to avoid duplication in accounting (Odum, 1996). In addition, as the tides are caused by the moon and the sun, which is different from other renewable resources. The renewable resource (R) in this study was calculated by the sum of the river, tide, and 
Table 1

Emergy synthesis of material and energy flows supporting Zengcheng in 2008.

\begin{tabular}{|c|c|c|c|c|c|c|c|}
\hline \multicolumn{2}{|c|}{ Type Item } & Raw data & $\begin{array}{l}\text { Raw } \\
\text { units }\end{array}$ & $\begin{array}{l}\text { Transformity } \\
\text { (sej/unit) }\end{array}$ & Reference & $\begin{array}{l}\text { Solar emergy } \\
\text { (sej) }\end{array}$ & $\begin{array}{l}\text { Em\$ } \\
\text { (USD) }\end{array}$ \\
\hline \multicolumn{8}{|c|}{ Renewable resource } \\
\hline 1 & Solar & $9.66 \mathrm{E}+16$ & $\mathrm{~J}$ & 1 & (Odum, 1996) & $1.20 \mathrm{E}+17$ & $4.03 \mathrm{E}+04$ \\
\hline 2 & Rain, chemical & $1.25 \mathrm{E}+16$ & $\mathrm{~J}$ & $3.05 \mathrm{E}+04$ & (Odum et al., 2000) & $3.81 \mathrm{E}+20$ & $1.28 \mathrm{E}+08$ \\
\hline 3 & Rain, geopotential & $5.72 \mathrm{E}+15$ & $\mathrm{~J}$ & $4.70 \mathrm{E}+04$ & (Odum et al., 2000) & $2.69 \mathrm{E}+20$ & $9.03 \mathrm{E}+07$ \\
\hline 4 & Wind & $8.05 \mathrm{E}+14$ & $\mathrm{~J}$ & $2.45 \mathrm{E}+03$ & (Odum et al., 2000) & $1.97 \mathrm{E}+18$ & $6.61 \mathrm{E}+05$ \\
\hline 5 & River, chemical & $4.10 \mathrm{E}+16$ & $\mathrm{~J}$ & $4.85 \mathrm{E}+04$ & (Odum, 1996) & $1.99 \mathrm{E}+21$ & $6.68 \mathrm{E}+08$ \\
\hline 6 & Tide & $1.28 \mathrm{E}+15$ & $\mathrm{~J}$ & $7.39 \mathrm{E}+04$ & (Odum, 1996; Odum et al., 2000) & $9.46 \mathrm{E}+19$ & $3.17 \mathrm{E}+07$ \\
\hline 7 & River, geopotential & $7.47 \mathrm{E}+15$ & $\mathrm{~J}$ & $4.66 \mathrm{E}+04$ & (Odum et al., 2000) & $3.48 \mathrm{E}+20$ & $1.17 \mathrm{E}+08$ \\
\hline 8 & Earth cycle & $3.70 \mathrm{E}+15$ & $\mathrm{~J}$ & $5.80 \mathrm{E}+04$ & (Odum et al., 2000) & $2.15 \mathrm{E}+20$ & $7.21 \mathrm{E}+07$ \\
\hline \multicolumn{8}{|c|}{ Renewable production } \\
\hline 9 & $\begin{array}{l}\text { NPP (including all vegetation types such as forests } \\
\text { and agriculture) }\end{array}$ & $3.99 \mathrm{E}+16$ & $\mathrm{~J}$ & $3.36 \mathrm{E}+05$ & $\begin{array}{l}\text { (Brown and Bardi, 2001) (Brown and } \\
\text { McClanahan, 1996) }\end{array}$ & $1.34 \mathrm{E}+22$ & $4.50 \mathrm{E}+09$ \\
\hline 10 & Livestock production & $6.46 \mathrm{E}+15$ & $\mathrm{~J}$ & $3.36 \mathrm{E}+06$ & (Brown and McClanahan, 1996) & $2.05 \mathrm{E}+22$ & $6.88 \mathrm{E}+09$ \\
\hline 11 & Fisheries production & $1.84 \mathrm{E}+14$ & $\mathrm{~J}$ & $3.36 \mathrm{E}+06$ & (Brown and McClanahan, 1996) & $6.18 \mathrm{E}+20$ & $2.07 \mathrm{E}+08$ \\
\hline \multicolumn{8}{|c|}{ Nonrenewable resource and their products } \\
\hline 12 & Electricity & $1.20 \mathrm{E}+16$ & $\mathrm{~J}$ & $1.59 \mathrm{E}+05$ & (Brandt-Williams, 2001) & $1.91 \mathrm{E}+21$ & $6.41 \mathrm{E}+08$ \\
\hline 13 & Coal & $1.27 \mathrm{E}+17$ & $\mathrm{~J}$ & $6.69 \mathrm{E}+04$ & (Odum, 1996) & $8.50 \mathrm{E}+21$ & $2.85 \mathrm{E}+09$ \\
\hline 14 & Natural gas & $2.48 \mathrm{E}+14$ & $\mathrm{~J}$ & $5.88 \mathrm{E}+04$ & (Brown, 2001) & $1.46 \mathrm{E}+19$ & $4.90 \mathrm{E}+06$ \\
\hline 15 & Diesel & $3.52 \mathrm{E}+15$ & $\mathrm{~J}$ & $1.11 \mathrm{E}+05$ & (Odum, 1996) & $3.91 \mathrm{E}+20$ & $1.31 \mathrm{E}+08$ \\
\hline 16 & Liquefied petroleum gas & $4.88 \mathrm{E}+14$ & $\mathrm{~J}$ & $1.18 \mathrm{E}+05$ & (Odum, 1996) & $5.76 \mathrm{E}+19$ & $1.93 \mathrm{E}+07$ \\
\hline 17 & Oil & $3.78 \mathrm{E}+14$ & $\mathrm{~J}$ & $8.90 \mathrm{E}+04$ & (Odum, 1996) & $3.36 \mathrm{E}+19$ & $1.13 \mathrm{E}+07$ \\
\hline 18 & Topsoil losses & $8.69 \mathrm{E}+14$ & $\mathrm{~J}$ & $7.40 \mathrm{E}+04$ & (Brown and Bardi, 2001) & $6.43 E+19$ & $2.16 \mathrm{E}+07$ \\
\hline 19 & Soil loss & $1.2 \mathrm{E}+12$ & $\mathrm{~g}$ & $1.68 \mathrm{E}+09$ & (Odum, 1996) & $2.02 \mathrm{E}+21$ & $6.78 \mathrm{E}+08$ \\
\hline 20 & Paper products & $3.16 \mathrm{E}+11$ & $\mathrm{~g}$ & $6.55 \mathrm{E}+09$ & (Odum, 1996) & $2.07 \mathrm{E}+21$ & $6.95 \mathrm{E}+08$ \\
\hline 21 & Plastic products & $6.56 \mathrm{E}+10$ & $\mathrm{~g}$ & $9.68 \mathrm{E}+09$ & (Brown and Arding, 1991) & $6.35 \mathrm{E}+20$ & $2.13 \mathrm{E}+08$ \\
\hline 22 & Pig iron & $1.66 \mathrm{E}+10 \mathrm{~g}$ & $\mathrm{~g}$ & $3.16 \mathrm{E}+09 \mathrm{~J} / \mathrm{g}$ & (Bargigli and Ulgiati, 2003) & $5.25 \mathrm{E}+19$ & $1.76 \mathrm{E}+07$ \\
\hline 23 & Glass & $2.15 \mathrm{E}+10$ & $\mathrm{~g}$ & $3.5 \mathrm{E}+09 \mathrm{~J} / \mathrm{g}$ & (Brown and Ulgiati, 2004) & $7.53 \mathrm{E}+19$ & $2.53 \mathrm{E}+07$ \\
\hline 24 & Textiles & $1.16 \mathrm{E}+11$ & $\mathrm{~g}$ & $1.34 \mathrm{E}+11$ & (Ascione et al., 2009) & $1.56 \mathrm{E}+22$ & $5.23 \mathrm{E}+09$ \\
\hline \multicolumn{8}{|c|}{ Currency flow } \\
\hline 25 & GDP & $7.34 \mathrm{E}+09$ & $\$$ & $1.16 \mathrm{E}+13$ & (Jiang et al., 2009) (Jiang et al., 2009) & $8.48 \mathrm{E}+22$ & $2.85 \mathrm{E}+10$ \\
\hline 26 & Tourism & $1.44 \mathrm{E}+08$ & $\$$ & $3.81 \mathrm{E}+12$ & (Ascione et al., 2009) & $5.49 \mathrm{E}+20$ & $1.84 \mathrm{E}+08$ \\
\hline 27 & Exports & $7.75 \mathrm{E}+08$ & $\$$ & $9.71 \mathrm{E}+12$ & (Jiang et al., 2009) & $7.53 \mathrm{E}+21$ & $2.53 \mathrm{E}+09$ \\
\hline 28 & Imports & $8.26 \mathrm{E}+08$ & $\$$ & $7.99 \mathrm{E}+12$ & (Jiang et al., 2009) & $6.60 \mathrm{E}+21$ & $2.21 \mathrm{E}+09$ \\
\hline \multicolumn{8}{|c|}{ Waste flow } \\
\hline 29 & Solid waste & $1.17 \mathrm{E}+15$ & $\mathrm{~J}$ & $1.80 \mathrm{E}+06$ & (Jiang et al., 2009) & $2.11 \mathrm{E}+21$ & $7.08 \mathrm{E}+08$ \\
\hline 30 & Waste water & $3.35 \mathrm{E}+10$ & Gallon & $8.77 \mathrm{E}+11$ & (Nelson et al., 2001) & $2.94 \mathrm{E}+22$ & $9.87 \mathrm{E}+09$ \\
\hline
\end{tabular}

earth cycle, $2.30 \mathrm{E}+21 \mathrm{sej}$. For the calculation of indigenous renewable production $\left(R_{1}\right)$, NPP was used to quantify the agricultural production (Wang et al., 2016), therefore the emergy value of $\mathrm{R}_{1}$ was the sum of NPP, livestock production, and fisheries production. Among all the indigenous renewable production, livestock production contributed the most with an emergy value of $2.05 \mathrm{E}+22$ sej, NPP was ranked second place with an emergy value of $1.34 \mathrm{E}+22 \mathrm{sej}$, and the lowest contribution came from fisheries production.

Nonrenewable sources $(\mathrm{N})$ include dispersed rural sources $\left(\mathrm{N}_{0}\right)$, concentrated use $\left(\mathrm{N}_{1}\right)$, and exported without use $\left(\mathrm{N}_{2}\right)$, with an emergy value of $3.14 \mathrm{E}+22 \mathrm{sej} . \mathrm{N}_{0}$ refers to the soil losses and topsoil losses in this study, which are consumed faster than they are regenerated (Jiang et al., 2008), with an emergy value of $2.08 \mathrm{E}+21 \mathrm{sej}$.
$\mathrm{N}_{1}$ and $\mathrm{N}_{2}$ mainly involve fuels and some products which were exported to other areas without use. Zengcheng is famous for clothing production, and most of the garments are exported. As is shown in Table 2, the emergy value of $\mathrm{N}_{2}$ was $1.84 \mathrm{E}+22 \mathrm{sej}$, which made up a large proportion of $\mathrm{N}$. The ratio of $\mathrm{N}_{1}$ to $\mathrm{N}$ was also large, and this indicates that the development of this district relies on nonrenewable resources to a great extent.

The calculation procedure is listed in Appendix A.

\subsection{Value of ecological services in value of Zengcheng for 2008}

The value of ecological services in Zengcheng was evaluated based on the formulas in Section 2 and are listed in Table 3. The total emergy value of ecosystem services was $1.95 \mathrm{E}+22$ sej with an

Table 2

Aggregate emergy flows of Zengcheng in 2008

\begin{tabular}{lll}
\hline Variable & Item & Solar emergy (sej) \\
\hline$R$ & Renewable source (river, tide) & $2.30 \mathrm{E}+21$ \\
$\mathrm{R}_{1}$ & Indigenous renewable production & $3.45 \mathrm{E}+22$ \\
$\mathrm{R}_{0}$ & Renewable emergy flow & $3.68 \mathrm{E}+22$ \\
$\mathrm{~N}$ & Nonrenewable sources & $3.14 \mathrm{E}+22$ \\
$\mathrm{~N}_{0}$ & Dispersed rural sources & $2.08 \mathrm{E}+21$ \\
$\mathrm{~N}_{1}$ & Concentrated use & $1.15 \mathrm{E}+10$ \\
$\mathrm{~N}_{2}$ & Exported without use & $1.23 \mathrm{E}+10$ \\
$\mathrm{U}$ & Total emergy used $\left(\mathrm{R}+\mathrm{N}_{0}+\mathrm{N}_{1}+\mathrm{IMP}\right)$ & $1.05 \mathrm{E}+22$ \\
$\mathrm{IMP}$ & Imported +10 & $2.19 \mathrm{E}+22$ \\
$\mathrm{EXP}$ & Exported & $6.60 \mathrm{E}+21$ \\
$\mathrm{~W}$ & Wasted emergy & $7.53 \mathrm{E}+21$ \\
\hline
\end{tabular}


emergy-dollar value of $\$ 6.17 \mathrm{E}+09$. The Supporting services accounted for the highest proportion of the emergy-dollar value with $84 \%$ of the total ecosystem service. The regulating services and the cultural services accounted for $13.2 \%$ and $2.8 \%$ respectively. The value of soil and water conservation represented the largest part with $78.9 \%$ of the total ecosystem services. This is because of abundant vegetation resources (Fig. 3).

The calculation procedure is listed in Appendix B.

\section{Discussion and policy implications}

\subsection{The sustainability of Zengcheng}

On the basis of the calculation the emergy flow in Zengcheng, a series of emergy-based indicators were employed to evaluate the sustainability of Zengcheng. These indicators can be divided into three types: social subsystem emergy indicators, economic subsystem emergy indicators, and natural subsystem emergy indicators (Wang et al., 2016). Table 4 presents the results of the evaluation.

\subsubsection{Social subsystem emergy analysis}

4.1.1.1. Emergy used per person. Emergy used per person (Ucap) is a measure of the living standards of a population, and this indicator is more effective than the fuel use per person (Jiang et al., 2008; Ulgiati et al., 1994). The value of Ucap in Zengcheng was $2.65 \mathrm{E}+16 \mathrm{sej}$, which is marginally lower than some developed regions but higher than the average value for China (Ascione et al., 2009; Jiang et al., 2008; Wang et al., 2016; Zhang et al., 2011) (Table 5). This indicates that the living standards for residents' of Zengcheng are an intermediate or above average level. One of the main reasons that the Ucap is so low is because of the low level of industrial or technological development. For example, the population of Zengcheng is $45 \%$ of the level in Dongying City, but the total emergy used in Zengcheng is only $15 \%$ of the value for Dongying City.

4.1.1.2. Empower density(ED). The empower density is the total emergy used by a country or region divided by the area. This indicator is usually used to measure the intensity and level of economic development, and the ED value of developed cities is always high. As shown in Table 4, the ED of Zengcheng was $1.35 \mathrm{E}+13 \mathrm{sej} /$ $\mathrm{m}^{2}$, this value is higher than the national level of $2.08 \mathrm{E}+12 \mathrm{sej} / \mathrm{m}^{2}$ but lower than some domestic and international developed cities, such as Beijing, Montreal, and Rome (Table 5). This reveals that the economic development level of Zengcheng is higher compared with some other Chinese cities, but lower than some developed cities. In other words, Zengcheng is in the medium development level.

\subsubsection{Economic subsystem emergy analysis}

4.1.2.1. Emergy to money ratio (EMR). The emergy to money ratio (EMR) is calculated via the total emergy used divided by the Gross Domestic Product (GDP). This index is used to quantify the emergy use efficiency, and a high EMR usually indicates low efficiency (Jiang et al., 2009). As shown in Table 4, the EMR of Zengcheng was $2.98 \mathrm{E}+12$. This value is lower than the EMR of Beijing and national average level, and it is proximate to the value of Dongying and Macao (Table 6). This reveals that the emergy use efficiency of Zengcheng is significantly higher than some cities of China. Generally speaking, the EMR of developed countries or regions is lower than undeveloped areas (Odum, 1996). However, the emergy use efficiencies of some developing cities can be markedly higher than developed cities, such as Xining with an EMR of 8.1 and Guiyang with an EMR of 22.2 (Jiang et al., 2009).

4.1.2.2. Emergy exchange ratio (EER). The emergy exchange ratio is used to quantify the gain and loss in external exchange, and it calculated via the imported emergy divided by the exported emergy. In general, developed regions which purchase raw materials have a larger EER than developing areas which sell the basic materials. As shown in Table 4, the EER of Zengcheng was 0.88 . This is higher than the national average level of 0.64 , but lower than some developed cities, such as Beijing at 1.08 and Macao at 1.34 (Table 6). This shows that the economic development of Zengcheng is at an intermediate level.

4.1.2.3. Emergy investment ratio (EIR). The emergy investment ratio is equal to the economic feedback emergy input divided by total local emergy input. If development of the economy depends on the consumption of local resources, the EIR will be extremely small. As shown in Table 4, the EIR of Zengcheng was 0.20, which is lower than the national average of 0.26 as well as the value for Dongying (0.41), and Macao (6.27) (Table 6). This indicates that the economic development of Zengcheng largely depends on the cost of local natural resources, and an adjustment of the industrial structure of Zengcheng is needed in future development.

\subsubsection{Natural subsystem emergy analysis}

4.1.3.1. Emergy self-support ratio (ESR). The emergy self-support ratio (ESR) is used to estimate the self-sufficiency of the system, which is equal to the local used emergy divided by total used emergy. This index also reflects the support ability of the environment, a high value for the ESR usually indicates that the natural environment is fragile. The ESR of Zengcheng was 0.70 (Table 4), which is close to the national average level of 0.77 and the value for Dongying (0.71), but much higher than Beijing (0.34) and Macao (0.02) (Table 7). This reveals that the used emergy of Zengcheng mostly comes from within the system itself rather than outside of Zengcheng, and this will produce significant great pressure on the ecosystem unless the pattern of economic growth is restructured and transformed.

4.1.3.2. Renewable to total used emergy ratio. The renewable to total used emergy ratio is calculated via the free renewable input divided by the total used emergy. As shown in Table 4, the renewable to total used emergy ratio of Zengcheng was 0.11 . This value was markedly higher than developed cities, such as Beijing at

Table 3

Ecological services of Zengcheng in 2008.

\begin{tabular}{|c|c|c|c|c|c|c|}
\hline Ecosystem service & Item & Raw data & Transformity (sej/unit) & Reference & Solar emergy (sej) & Em\$ (USD) \\
\hline \multirow[t]{2}{*}{ Regulating services } & Gas regulation $(\mathrm{g})$ & $3.34 \mathrm{E}+12$ & $5.11 \mathrm{E}+07$ & (Li et al., 2007) & $1.71 \mathrm{E}+20$ & $5.74 \mathrm{E}+07$ \\
\hline & waste disposal (g) & $7.93 \mathrm{E}+11$ & $3.04 \mathrm{E}+09$ & (Brown and Ulgiati, 2011) & $2.41 \mathrm{E}+21$ & $8.09 \mathrm{E}+08$ \\
\hline \multirow[t]{2}{*}{ Supporting services } & Water resource conservation (g) & $1.50 \mathrm{E}+15$ & $6.65 \mathrm{E}+05$ & (Li et al., 2007) & $9.97 \mathrm{E}+20$ & $3.35 \mathrm{E}+08$ \\
\hline & Soil and water conservation $(\mathrm{J})$ & $8.99 \mathrm{E}+16$ & $7.40 \mathrm{E}+04$ & (Brown and Bardi, 2001) & $1.54 \mathrm{E}+22$ & $5.17 \mathrm{E}+09$ \\
\hline Cultural services & Recreation and culture $(\$)$ & $1.44 \mathrm{E}+08$ & $3.81 \mathrm{E}+12$ & (Jiang et al., 2009) & $5.49 \mathrm{E}+20$ & $1.84 \mathrm{E}+08$ \\
\hline Total & & & & & $1.95 \mathrm{E}+22$ & $6.17 \mathrm{E}+09$ \\
\hline
\end{tabular}




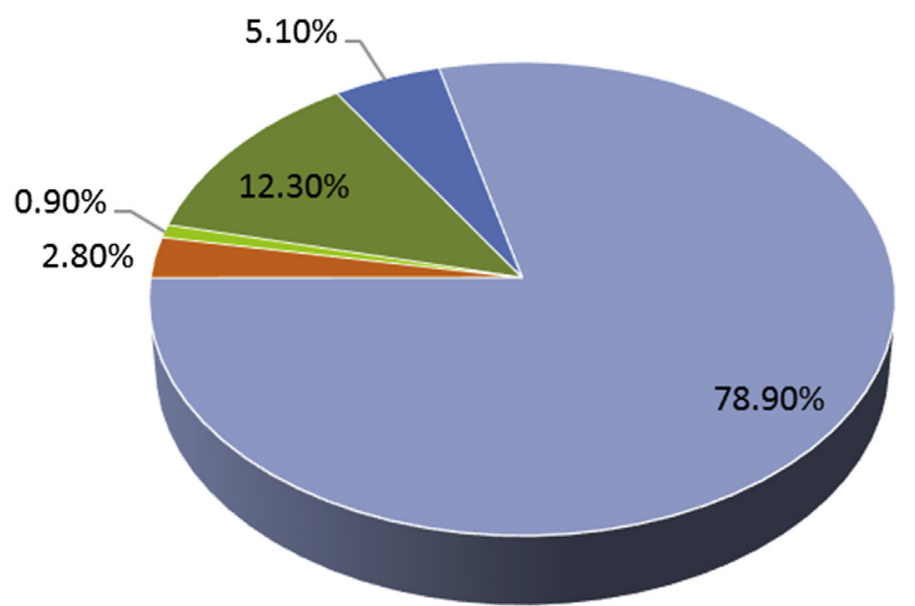

- Gas regulation

- Water resource conservation

- Recreation and culture
" waste disposal

- Soil and water conservation

Fig. 3. The proportion of ecosystem services of Zengcheng in 2008.

Table 4

Emergy indicators of Zengcheng.

\begin{tabular}{|c|c|c|c|}
\hline Item & Expression & Value & Unit \\
\hline \multicolumn{4}{|l|}{ Social subsystem emergy analysis } \\
\hline 1. Total emergy used (U) & $\mathrm{R}+\mathrm{N} 0+\mathrm{N} 1+\mathrm{IMP}$ & $2.19 \mathrm{E}+22$ & Sej \\
\hline 2. Per capita Renewable resources $\left(\mathrm{R}_{c a p}\right)$ & R/population & $2.78 \mathrm{E}+15$ & sej/cap \\
\hline 3. Per capita emergy (Ucap) & U/population & $2.65 \mathrm{E}+16$ & sej/cap \\
\hline 4. Per capita nonrenewable resources $\left(\mathrm{N}_{c a p}\right)$ & $\left(\mathrm{N}_{0}+\mathrm{N}_{1}+\mathrm{F}\right) /$ population & $2.37 \mathrm{E}+16$ & sej/cap \\
\hline 5. Empower density (ED) & U/area & $1.35 \mathrm{E}+13$ & $\mathrm{sej} / \mathrm{m}^{2}$ \\
\hline \multicolumn{4}{|l|}{ Economic subsystem emergy analysis } \\
\hline 6. Ratio of electricity to total emergy used & Electricity/U & 0.08 & \\
\hline 7. Emergy to money ratio (EMR) & $\mathrm{U} / \mathrm{GDP}$ & $2.98 \mathrm{E}+12$ & sej/\$ \\
\hline 8. Emergy exchange ratio & IMP/EXP & 0.88 & \\
\hline 9. Emergy yield ratio (EYR) & $(\mathrm{R}+\mathrm{N}+\mathrm{IMP}) / \mathrm{IMP}$ & 6.11 & \\
\hline 10. Emergy investment ratio (EIR) & $\mathrm{IMP} /(\mathrm{R}+\mathrm{N})$ & 0.20 & - \\
\hline \multicolumn{4}{|l|}{ Natural subsystem emergy analysis } \\
\hline 11. Emergy self-support ratio (ESR) & $\left(\mathrm{R}+\mathrm{N}_{0}+\mathrm{N}_{1}\right) / \mathrm{U}$ & 0.70 & - \\
\hline 12. Renewable to total used emergy ratio & $\mathrm{R} / \mathrm{U}$ & 0.11 & \\
\hline 13. Environmental loading ratio (ELR) & $(\mathrm{U}-\mathrm{R}) / \mathrm{R}$ & 8.52 & - \\
\hline 14. Emergy sustainability index (ESI) & EYR/ELR & 0.72 & - \\
\hline 15. Waste to renewable emergy ratio & $\mathrm{W} / \mathrm{R}$ & 13.70 & - \\
\hline 16. Waste to total emergy used ratio & $\mathrm{W} / \mathrm{U}$ & 1.44 & \\
\hline
\end{tabular}

1.84E-03 and Macao at 1.34E-03, and was proximate to the national average value of China and the value for Dongying (Table 7). The high value of this index indicates that the economic development of Zengcheng consumes significant amount of natural resources.

4.1.3.3. Environmental loading ratio (ELR). The environmental loading ratio is obtained through the nonrenewable input emergy divided by renewable input emergy. A large ELR value indicates that the emergy use of this system is highly-intensive, and that the economic development is at a high level with a large pressure on the environment. The ELR of Zengcheng was 8.52. This value is close to the national average value of 8.99 and much smaller than developed cities, such as Beijing at 531.23 and Macao at 743 (Table 7). This indicates that the pressure on the ecological

Table 5

Comparison of social subsystem emergy for selected cities.

\begin{tabular}{|c|c|c|c|c|c|c|}
\hline City & Total emergy used (sej) & Surface $\left(\mathrm{m}^{2}\right)$ & Population (people) & Emergy used per person (sej/cap) & Empower density $\left(\mathrm{sej} / \mathrm{m}^{2}\right)$ & Sources \\
\hline Zengcheng (2008) & $2.19 \mathrm{E}+22$ & $1.62 \mathrm{E}+09$ & $8.27 \mathrm{E}+05$ & $2.65 \mathrm{E}+16$ & $1.35 \mathrm{E}+13$ & Present study \\
\hline China (2004) & $1.99 \mathrm{E}+25$ & $9.57 \mathrm{E}+12$ & $1.30 \mathrm{E}+09$ & $1.53 \mathrm{E}+16$ & $2.08 \mathrm{E}+12$ & (Jiang et al., 2008) \\
\hline Dongying (2009) & $1.43 \mathrm{E}+23$ & $7.92 \mathrm{E}+09$ & $1.85 \mathrm{E}+06$ & $6.18 \mathrm{E}+16$ & $1.44 \mathrm{E}+13$ & (Wang et al., 2016) \\
\hline Beijing (2004) & $6.51 \mathrm{E}+23$ & $1.76 \mathrm{E}+10$ & $1.49 \mathrm{E}+07$ & $4.36 \mathrm{E}+16$ & $3.69 \mathrm{E}+13$ & (Zhang et al., 2011) \\
\hline Montreal (2005) & $1.15 \mathrm{E}+23$ & $4.99 \mathrm{E}+08$ & $1.85 \mathrm{E}+06$ & $6.25 \mathrm{E}+16$ & $2.31 \mathrm{E}+14$ & (Vega-Azamar et al., 2013) \\
\hline Rome (2002) & $1.38 \mathrm{E}+23$ & $1.29 \mathrm{E}+09$ & $2.54 \mathrm{E}+06$ & $5.45 \mathrm{E}+16$ & $1.07 \mathrm{E}+14$ & (Ascione et al., 2009) \\
\hline
\end{tabular}


Table 6

Comparison of the economic subsystem emergy analysis emergy for selected cities.

\begin{tabular}{|c|c|c|c|c|}
\hline City & Emergy to money ratio (EMR) & Emergy exchange ratio & Emergy investment ratio (EIR) & Sources \\
\hline Zengcheng (2008) & $2.98 \mathrm{E}+12$ & 0.88 & 0.20 & Present study \\
\hline Beijing (2004) & $1.22 \mathrm{E}+13$ & 1.08 & - & (Zhang et al., 2011) \\
\hline China (2004) & $1.18 \mathrm{E}+13$ & 0.64 & 0.26 & (Jiang et al., 2008) \\
\hline Dongying (2009) & $4.53 \mathrm{E}+12$ & - & 0.41 & (Wang et al., 2016) \\
\hline Macao (2004) & $2.39 \mathrm{E}+12$ & 1.34 & 6.27 & (Lei et al., 2008) \\
\hline
\end{tabular}

Table 7

Comparison of natural subsystem emergy analysis for selected cities.

\begin{tabular}{|c|c|c|c|c|c|}
\hline City & $\begin{array}{l}\text { Emergy self-support ratio } \\
\text { (ESR) }\end{array}$ & $\begin{array}{l}\text { Renewable to total used emergy } \\
\text { ratio }\end{array}$ & $\begin{array}{l}\text { Environmental loading ratio } \\
\text { (ELR) }\end{array}$ & $\begin{array}{l}\text { Emergy sustainability index } \\
\text { (ESI) }\end{array}$ & Sources \\
\hline $\begin{array}{c}\text { Zengcheng } \\
\text { (2008) }\end{array}$ & 0.70 & 0.11 & 8.52 & 0.72 & Present study \\
\hline Beijing (2004) & 0.34 & $1.84 \mathrm{E}-3$ & 531.23 & - & (Zhang et al., 2011) \\
\hline China (2004) & 0.77 & 0.10 & 8.99 & - & (Jiang et al., 2008) \\
\hline $\begin{array}{l}\text { Dongying } \\
(2009)\end{array}$ & 0.71 & 0.19 & 4.3 & 0.79 & (Wang et al., 2016) \\
\hline Macao (2004) & 0.02 & $1.34 \mathrm{E}-03$ & 743 & $1.00 \mathrm{E}-3$ & (Lei et al., 2008) \\
\hline Montreal (2004) & - & 0.03 & 30.32 & 0.03 & $\begin{array}{l}\text { (Vega-Azamar et al., } \\
\text { 2013) }\end{array}$ \\
\hline
\end{tabular}

environment is not very heavy and that the industry of Zengcheng is not particularly advanced. Zengcheng is rich in natural resources and also has many ecological services. These services can help to reduce the environmental load and ensure the health of ecological systems.

4.1.3.4. Emergy sustainability index (ESI). The emergy sustainability index was proposed by Ulgiati in 1998 (Ulgiati and Brown, 1998), and it is calculated by the emergy yield ratio divided by the environmental loading ratio. This index can be used to evaluate the sustainability of the development of a city. Ulgiati and his colleagues also determined the quantitative standards. When the ESI $<1$, the area should be well developed. ESI values in the range of 1-10 may indicate a developing area. The ESI of Zengcheng was 0.72 , much higher than Macao at $1.34 \mathrm{E}-03$ and Montreal at 0.03 but close to the value for Dongying (Table 7). This shows that the industrial economic development of Zengcheng is still markedly different from developed cities, and that the development of this city largely relies on the consumption of indigenous resources. Therefore, the industrial structure should be adjusted in the future development of Zengcheng.

All these indicators revealed that the economic development of Zengcheng is at an intermediate position in the country, and that the sustainability is at a relatively low level. In future development, some strategies should be carried out, such as conforming the energy and resources usage to a reasonable structure, reducing the consumption of fossil fuels, developing utilization of the biomass energy, restructuring the pattern of economic growth and developing specialty industries that are beneficial to the protection of the ecological environment. The three main functional areas of Zengcheng can be treated as three major economic circles, and these areas should develop in a complementary, interactive, and coordinated manner, and then enhance the comprehensive competitiveness of this city.

\subsection{The ecological services of Zengcheng}

The total emergy of ecological services in Zengcheng was $1.95 \mathrm{E}+22$ sej (Table 3 ). The ecological services empower density (ESED) was calculated as $1.20 \mathrm{E}+13 \mathrm{sej} / \mathrm{m}^{2}$. In contrast, the emergy value of forest ecological services in the United States was $3.74 \mathrm{E}+23$ sej/yr. This value was based on a US forest area of $7.8 \mathrm{E}+11 \mathrm{~m}^{2}$. The ESED was determined to be $4.79 \mathrm{E}+11 \mathrm{sej} / \mathrm{m}^{2}$ (Campbell and Brown, 2012), which is markedly smaller than the ESED of Zengcheng. The emergy value of ecosystem services from Maryland forests was $1.38 \mathrm{E}+22 \mathrm{sej}$, and the ESED was calculated to be $1.38 \mathrm{E}+12 \mathrm{sej} / \mathrm{m}^{2}$ with a forest area of was $1.0 \mathrm{E}+10 \mathrm{~m}^{2}$ (Campbell and Tilley, 2014). This is also lower than the value of Zengcheng. In addition, since the Gross Domestic Product (GDP) of Zengcheng was \$7.34E+09 and the total emergy-dollar value of ecological services of Zengcheng was 6.17E+09 Em\$, the Em dollar was closer to the GDP. Therefore, Zengcheng provides substantial ecological services and increases the overall ecological capacity of this metropolitans region. This should be kept in mind during future urban planning and development in this region.

\section{Conclusions}

This study evaluates the sustainability of Zengcheng via holistic considerations of its economy, society, and ecosystem and quantifies the value of ecological services based on emergy analysis. Via calculating environmental and economic flows within and outside the social-economic-natural complex of Zengcheng, this study calculates three major types of indicators (social subsystem emergy indicators, economic subsystem emergy indicators, and natural subsystem emergy indicators) and then compares these indicators with those of selected cities and regions. The results indicate that development of Zengcheng is mainly reliant on the consumption of indigenous resources. The industrial level of this city is higher than the average level in China but lower than developed cities or regions, therefore the pattern of economic growth should be restructured and transformed. On the other hand, since the emergy value of ecological services in Zengcheng is very high, a large amount of ecological services can be provided by Zengcheng, and the overall ecological capacity of Guangzhou will be expanded. In this way, Zengcheng will be able to share the economic and population pressures of Guangzhou. As a satellite town, Zengcheng plays an important role in the development of Guangzhou. Since the overall strategic development plan of Zengcheng was implemented in 2008, an evaluation of sustainability and the value of ecological services based the data from 2008 may be helpful for determining the effectiveness of these policies. 


\section{Acknowledgments}

This research is supported by Commissioned Project of Guangzhou Government (No. 06E9881201), the Science and Technology Service Network Initiative (No. KFJ-EW-STS-002-7), the National Natural Science Foundation of China (No. 71403145) and the China Scholarship Council (CSC No. 201506225033). We would like to thank Dr. Edward C. Mignot of Shandong University for linguistic advice.

\section{Appendix A}

1. Solar energy: land area $=1.62 \mathrm{E}+09 \mathrm{~m}^{2}$. Insolation $=7.45 \mathrm{E}+07 \mathrm{~J} / \mathrm{m}^{2} / \mathrm{yr}$. Albedo $=0.20(\%$ given as a decimal). Energy $(\mathrm{J})=(\text { area including shelf })^{*}$ (average insolation $)^{*}(1$-albedo $)=9.66 \mathrm{E}+15 \mathrm{~J} / \mathrm{yr}$. Transformity $=1 \mathrm{sej} / \mathrm{J}$.

2. Rain, chemical potential energy: Land area $=1.62 \mathrm{E}+09 \mathrm{~m}^{2}$. Rain $=1.96 \mathrm{~m} / \mathrm{yr}$. Evapotranspiration rate $=1.57 \mathrm{~m} / \mathrm{yr}$ (estimated as $80 \%$ of total rain). Energy (land) $(\mathrm{J})=($ area) *(Evapotrans) ${ }^{*}($ Gibbs no.) $=1.25 \mathrm{E}+16 \mathrm{~J} / \mathrm{yr}$. Transformity $=3.05 \mathrm{E}+04 \mathrm{sej} / \mathrm{J}$.

3. Rain, geopotential energy: Land area $=1.62 \mathrm{E}+09 \mathrm{~m} 2$. Rain $=1.96 \mathrm{~m} / \mathrm{yr}$. Runoff rate $=0.20 \%$ (percent, given as a decimal). Average elevation $=91.98 \mathrm{~m}$. Energy $(\mathrm{J})=($ area $)$ *(rainfall $)^{*} \%$ runoff $)^{*}(\text { avg elevation })^{*}\left(1000 \mathrm{~g} / \mathrm{m}^{3}\right)$ (gravity) $=5.72 \mathrm{E}+15 \mathrm{~J} / \mathrm{yr}$. Transformity $=4.70 \mathrm{E}+04 \mathrm{sej} / \mathrm{J}$.

4. Wind energy: Area $=1.62 \mathrm{E}+09 \mathrm{~m}^{2}$. Density of air $=1.30 \mathrm{E}+00 \mathrm{~kg} / \mathrm{m}^{3}$. Velocity $=2.3 \mathrm{~m} / \mathrm{s}$. Drag coefficient $=1.00 \mathrm{E}-3$. Energy $(\mathrm{J})=(\text { area })^{*}(\text { air density })^{*}($ drag

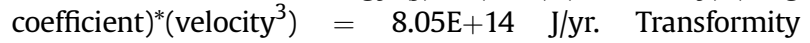
$=2.45 \mathrm{E}+03 \mathrm{sej} / \mathrm{J}$.

5. River chemical: Runoff (Zengjiang and Dongjiang $)=8.29 \mathrm{E}+09 \mathrm{~m}^{3} / \mathrm{yr}$. Energy $(\mathrm{J})=$ Runoff $* 4.94 \mathrm{E}+06=4.10 \mathrm{E}+16 \mathrm{~J} / \mathrm{yr}$.

6. Tidal energy: Continental shelf area $=1.71 \mathrm{E}+07 \mathrm{~m}^{2}$. Average tide range $=4.50 \mathrm{~m}$. Density $=1.03 \mathrm{E}+\mathrm{kg} / \mathrm{m} 3$. Tides $/$ year $=7.30 \mathrm{E}+02$. Energy $(\mathrm{J})=(\text { shelf })^{*}(0.5)^{*}(\text { tides } / \mathrm{y})^{*}($ mean tidal range $)^{\wedge} 2^{*}$ (density of seawater $)^{*}($ gravity $)=1.28 \mathrm{E}+15 \mathrm{~J} /$ yr. Transformity $=7.39 \mathrm{E}+04 \mathrm{sej} / \mathrm{J}$.

7. Average river geopotential work: Runoff (Zengjiang and Dongjiang) $=8.29 \mathrm{E}+09 \mathrm{~m}^{3} / \mathrm{yr}$. Average elevation $=9.20 \mathrm{E}+02 \mathrm{~m}$. Energy $(\mathrm{J})=($ runoff $) *\left(1.00 \mathrm{E}+03 \mathrm{~kg} / \mathrm{m}^{3}\right)$ ${ }^{*}(\text { elevation })^{*}\left(9.8 \mathrm{~m} / \mathrm{sec}^{2}\right)=7.47 \mathrm{E}+15 \mathrm{~J} / \mathrm{yr}$.

8. Earth cycle: Land area $=1.62 \mathrm{E}+09 \mathrm{~m}^{2}$. Heat flow $=7.22 \mathrm{E}-$ $02 \mathrm{~J} / \mathrm{m}^{2} / \mathrm{s}$. Energy $(\mathrm{J})=(\text { Land area })^{*}($ Heat flow $)=3.70 \mathrm{E}+15 \mathrm{~J} /$ yr. Transformity $=5.80 \mathrm{E}+04 \mathrm{sej} / \mathrm{J}$.

9. Net Primary Production: NPP $=1.19 \mathrm{E}+12 \mathrm{~g} \mathrm{C} / \mathrm{yr}$. Energy $(\mathrm{J})=(\mathrm{NPP})^{*}(8 \mathrm{KCal} / \mathrm{g})^{*}(4186 \mathrm{~J} / \mathrm{KCal})=3.99 \mathrm{E}+16 \mathrm{~J} / \mathrm{yr}$. Transformity $=3.36 \mathrm{E}+05 \mathrm{sej} / \mathrm{J}$.

10. Livestock production: Meat $=7.53 \mathrm{E}+04 \mathrm{t}$. Energy content $=1.00 \mathrm{E}+10 \mathrm{~J} / \mathrm{t}$. Milk $=9.71 \mathrm{E}+04 \mathrm{t}$. Energy content $=4.50 \mathrm{E}+10 \mathrm{~J} / \mathrm{t}$. Egg $=8.33 \mathrm{E}+04 \mathrm{t}$. Energy content $=1.15 \mathrm{E}+10 \mathrm{~J} / \mathrm{t}$. Energy $(\mathrm{J})=(\text { Total production })^{*}($ energy content $)=6.46 \mathrm{E}+15 \mathrm{~J} / \mathrm{yr}$. Transformity $=3.36 \mathrm{E}+06 \mathrm{sej} / \mathrm{J}$.

11. Fisheries production: Fish catch $=3.91 \mathrm{E}+04 \mathrm{t}$. Energy content $=4.70 \mathrm{E}+09 \mathrm{~J} / \mathrm{t}$. Energy $(\mathrm{J})=($ Total production $)$ $*($ energy content $)=1.84 \mathrm{E}+14 \mathrm{~J}$. Transformity $=3.36 \mathrm{E}+06 \mathrm{sej} /$ J.

12. Electricity: Consumption $=3.32 \mathrm{E}+09 \mathrm{kw} / \mathrm{h}$. Energy content $=3.59 \mathrm{E}+06 \mathrm{~J} / \mathrm{Kw}$ h. Energy $(\mathrm{J})=$ (Consumption) $*($ energy content $)=1.20 \mathrm{E}+16 \mathrm{~J}$. Transformity $=1.59 \mathrm{E}+05$ sej/J.

13. Coal: Consumption $=3.99 \mathrm{E}+06 \mathrm{t} / \mathrm{yr}$. Energy content $=3.18 \mathrm{E}+10 \mathrm{~J} / \mathrm{t}$. Energy $(\mathrm{J})=(\text { Consumption })^{*}($ energy content $)=1.27 \mathrm{E}+17 \mathrm{~J}$. Transformity $=6.69 \mathrm{E}+04 \mathrm{sej} / \mathrm{J}$.
14. Natural gas: Consumption $=5.11 \mathrm{E}+06 \mathrm{~m} 3 / \mathrm{yr}$. Energy $(\mathrm{J})=(\text { Natural gas })^{*}(8966 \mathrm{kcal} / \mathrm{m} 3)^{*}(4186 \mathrm{~J} / \mathrm{kcal})=1.92 \mathrm{E}+14$. Transformity $=5.88 \mathrm{E}+04 \mathrm{sej} / \mathrm{J}$.

15. Diesel: Consumption $=7.64 \mathrm{E}+07 \mathrm{~kg} / \mathrm{yr}$. Energy content $=46.04 \mathrm{MJ} / \mathrm{t}$. Energy $(\mathrm{J})=(\text { Consumption })^{*}($ energy content $)=3.52 \mathrm{E}+15 \mathrm{~J}$. Transformity $=1.11 \mathrm{E}+05 \mathrm{sej} / \mathrm{J}$.

16. Liquefied petroleum gas: Consumption $=9.73 \mathrm{E}+06 \mathrm{~kg} / \mathrm{yr}$. Energy content $=5.02 \mathrm{E}+07 \mathrm{~J} / \mathrm{t}$. Energy $(\mathrm{J})=($ Consumption $)$ $*($ energy content $)=4.88 \mathrm{E}+14 \mathrm{~J}$. Transformity $=1.18 \mathrm{E}+05 \mathrm{sej} /$ J.

17. Oil: Consumption $=4.30 \mathrm{E}+06 \mathrm{~kg} / \mathrm{yr}$. Energy content $=87.92 \mathrm{MJ} / \mathrm{kg}$. Energy $(\mathrm{J})=(\text { Consumption })^{*}($ energy content $)=3.78 \mathrm{E}+14 \mathrm{~J}$. Transformity $=8.90 \mathrm{E}+04 \mathrm{sej} / \mathrm{J}$.

18. Topsoil losses: Soil loss $=7.42 \mathrm{E}+02 \mathrm{~g} / \mathrm{m}^{2} / \mathrm{yr}$. Land area $=1.62 \mathrm{E}+09 \mathrm{~m}^{2}$. Average organic content $(\%)=3.2 \%$. Energy $(\mathrm{J})=(\text { Soil loss })^{*}(\text { Harvested cropland })^{*}(\%$ organic $)$ *(5.4 $\mathrm{kcal} / \mathrm{g}) *(4186 \mathrm{~J} / \mathrm{Kcal})=8.69 \mathrm{E}+14 \mathrm{~J}$. Transformity $=7.40 \mathrm{E}+04 \mathrm{sej} / \mathrm{J}$.

19. Soil loss: Land area $=1.62 \mathrm{E}+09 \mathrm{~m}^{2}$. Soil loss $=7.42 \mathrm{E}+02 \mathrm{~g} /$ $\mathrm{m}^{2} / \mathrm{yr}$. Mass $(\mathrm{g})=1.20 \mathrm{E}+12 \mathrm{~g}$. Transformity $=1.68 \mathrm{E}+09 \mathrm{sej} / \mathrm{g}$.

20. Paper products: Paper production $=3.16 \mathrm{E}+11 \mathrm{~g}$. Transformity $=6.55 \mathrm{E}+09 \mathrm{sej} / \mathrm{g}$.

21. Plastic products: Plastic production $=6.56 \mathrm{E}+10 \mathrm{~g}$. Transformity $=9.68 \mathrm{E}+09 \mathrm{sej} / \mathrm{g}$.

22. Pig iron: Pig iron production $=6.56 \mathrm{E}+10 \mathrm{~g}$. Transformity $=9.68 \mathrm{E}+09 \mathrm{sej} / \mathrm{g}$.

23. Glass: Glass production $=1.66 \mathrm{E}+10 \mathrm{~g}$. Transformity $=3.16 \mathrm{E}+09 \mathrm{sej} / \mathrm{g}$.

24. Textiles: Textiles production $=1.16 \mathrm{E}+11 \mathrm{~g}$. Transformity $=1.34 \mathrm{E}+11 \mathrm{sej} / \mathrm{g}$.

25. GDP: GDP $=7.34 \mathrm{E}+09 \$$. Transformity $=1.16 \mathrm{E}+13 \mathrm{sej} / \$$.

26. Tourism: Tourism $=1.44 \mathrm{E}+08 \$$. Trantsformity $=3.81 \mathrm{E}$ +12 sej/\$.

27. Exported productions: Export $=7.75 \mathrm{E}+08 \$ \mathrm{yr}$. Transformity $=9.71 \mathrm{E}+12 \mathrm{sej} / \$$.

28. Imported productions: Imported $=8.26 \mathrm{E}+08 \$ / \mathrm{yr}$. Transformity $=7.99 \mathrm{E}+12 \mathrm{sej} / \$$.

29. Solid waste: Solid waste $=3.49 \mathrm{E}+05 \mathrm{t} / \mathrm{yr}$. Energy content per ton $=3.35 \mathrm{E}+09 \mathrm{~J} / \mathrm{t}$. Energy $(\mathrm{J})=(\text { Solid waste })^{*}($ energy content $)=1.17 \mathrm{E}+15 \mathrm{~J}$. Transformity $=1.80 \mathrm{E}+06 \mathrm{sej} / \mathrm{J}$.

30. Waste water: Waste water $=3.35 \mathrm{E}+10$ Gallon. Transformity $=8.77 \mathrm{E}+11 \mathrm{sej} /$ Gallon .

\section{Appendix B}

\section{Regulating services}

Fixed carbon dioxide: $\mathrm{NPP}=1.19 \mathrm{E}+12 \mathrm{~g} \mathrm{C} / \mathrm{yr} . \mathrm{T}=5.11 \mathrm{E}+07 \mathrm{sej} / \mathrm{g}$. $\mathrm{E}=1.63^{*} \mathrm{NPP}^{*} \mathrm{~T}=9.91 \mathrm{E}+19 \mathrm{sej}$.

Released oxygen: NPP $=1.19 \mathrm{E}+12 \mathrm{~g} \mathrm{C} / \mathrm{yr}$. T $=5.11 \mathrm{E}+07 \mathrm{sej} / \mathrm{g}$. $\mathrm{E}=1.19^{*} \mathrm{NPP}^{*} \mathrm{~T}=7.18 \mathrm{E}+19 \mathrm{sej}$.

Pollution treatment: $\mathrm{S}=7.78 \mathrm{E}+08 \mathrm{~m}^{2} . \mathrm{U}_{(\mathrm{so} 2)}=8.87 \mathrm{E}+04 \mathrm{~g} / \mathrm{hm}^{2}$. $\mathrm{u}_{(\text {dust })}=1.01 \mathrm{E}+07 \mathrm{~g} / \mathrm{hm}^{2} . \mathrm{T}=3.04 \mathrm{E}+09 \mathrm{sej} / \mathrm{g}$.

$\mathrm{E}=\sum \mathrm{S}^{*} \mathrm{u}_{\mathrm{i}} * \mathrm{~T}=2.41 \mathrm{E}+21 \mathrm{sej}$.

\section{Supporting services}

Water resource conservation: $\mathrm{P}=1.96 \mathrm{~m} / \mathrm{yr} . \mathrm{E}=1.57 \mathrm{~m} / \mathrm{yr}$ (estimated as $80 \%$ of total rain).

$\mathrm{S}=7.78 \mathrm{E}+08 \mathrm{~m}^{2} . \rho=1.00 \mathrm{E}+03 \mathrm{~kg} / \mathrm{m}^{3} . \mathrm{G}=4.94 \times 106 \mathrm{~J} / \mathrm{g}$. $\mathrm{T}=6.66 \mathrm{E}+05 \mathrm{sej} / \mathrm{g} . \mathrm{E}=(\mathrm{P}-\mathrm{E})^{*} \mathrm{~S}^{*} \rho^{*} \mathrm{G}^{*} \mathrm{~T}=9.97 \mathrm{E}+20 \mathrm{sej}$.

Soil and water conservation: $\mathrm{d}=7.42 \mathrm{E}+02 \mathrm{~g} / \mathrm{m}^{2} / \mathrm{yr}$. $\mathrm{S}=7.78 \mathrm{E}+08 \mathrm{~m}^{2} . \mathrm{u}=19.42 \mathrm{~kJ} / \mathrm{g} . \mathrm{T}=7.40 \mathrm{E}+04 \mathrm{sej} / \mathrm{g} . \mathrm{E}=\left(\mathrm{d}^{*} \mathrm{~s} / 5.1 \%-\right.$ $\left.\mathrm{d}^{*} \mathrm{~s}\right)^{*} \mathrm{u}^{*} \mathrm{~T}=1.54 \mathrm{E}+22 \mathrm{sej}$. 
Biodiversity protection: $\mathrm{N}=64$ species. $\mathrm{T}=6.45 \mathrm{E}+19 \mathrm{sej} / \mathrm{spe}-$ cies. $\mathrm{E}=\mathrm{N}^{*} \mathrm{~T}=4.13 \mathrm{E}+21 \mathrm{sej}$.

\section{Cultural services}

Tourism $=1.44 \mathrm{E}+08 \$ . \mathrm{T}=3.81 \mathrm{E}+12 \mathrm{sej} / \$ . \mathrm{E}=$ Tourism $^{*} \mathrm{~T}$ $=5.49 \mathrm{E}+20 \mathrm{sej}$.

\section{References}

Ascione, M., Campanella, L., Cherubini, F., Ulgiati, S., 2009. Environmental driving forces of urban growth and development: an emergy-based assessment of the city of Rome, Italy. Landsc. Urban Plan. 93, 238-249.

Bargigli, S., Ulgiati, S., 2003. Emergy and life-cycle assessment of steel production in Europe. Emergy Synthesis 2, 141-156. http://www.cep.ees.ufl.edu/emergy/ documents/conferences/ERC02_2001/ERC02_2001_Chapter_10.pdf.

Brandt-Williams, S.L., 2001. Handbook of emergy evaluation: a compendium of data for emergy computation issued in a series of Folios. Folio\# 4. Emergy of Florida Agriculture, pp. 32611-36450. http://cep.ees.ufl.edu/emergy/documents/folios/ Folio_04.pdf.

Brown, M.T., 2001. Emergy Synthesis: Theory and applications of the emergy methodology. Proceedings of a conference held at Gainesville, FL September 1999. In: The Center for Environmental Policy. University of Florida, Gainesville, p. 319.

Brown, M., Arding, J., 1991. Transformities working paper. Center for Wetlands. University of Florida, Gainesville.

Brown, M., Ulgiati, S., 2011. Handbook of emergy evaluation Folio 6: The global emergy budget and the emergy of global processes revisited. Center for Environmental Policy. University of Florida, Gainesville, FL.

Brown, M.T., Bardi, E., 2001. Handbook of Emergy Evaluation Folio 3: Emergy of Ecosystems. Center for Environmental Policy. University of Florida, Gainesville, 90p. http://cep.ees.ufl.edu/emergy/documents/folios/Folio_03.pdf.

Brown, M.T., McClanahan, T., 1996. Emergy analysis perspectives of Thailand and Mekong River dam proposals. Ecol. Model 91, 105-130.

Brown, M.T., Ulgiati, S., 2004. Emergy analysis and environmental accounting. Encycl. Energy 2, 329-354.

Campbell, E.T., Brown, M.T., 2012. Environmental accounting of natural capital and ecosystem services for the US National Forest System. Environ. Dev. Sustain 14, $691-724$.

Campbell, E.T., Tilley, D.R., 2014. Valuing ecosystem services from Maryland forests using environmental accounting. Ecosys. Serv 7, 141-151.

Cohen, B., 2006. Urbanization in developing countries: Current trends, future projections, and key challenges for sustainability. Technol. Soc 28, 63-80.

Costanza, R., d'Arge, R., de Groot, R., Faber, S., Grasso, M., Hannon, B., Limburg, K., Naeem, S., O'Neill, R., Paruelo, J., Raskin, R., Sutton, P., van den Belt, M., 1997. The value of the world's ecosystem services and natural capital. Nature 387, 253-260.

Dolman, A., Verhagen, A., 2003. Land Use and Global Environmental Change, Global Environmental Change and Land Use. Springer, pp. 3-13.

Fahmi, F.Z., Hudalah, D., Rahayu, P., Woltjer, J., 2014. Extended urbanization in small and medium-sized cities: the case of Cirebon, Indonesia. Habitat Int. 42, 1-10.

Fang, D., Chen, S., Chen, B., 2015. Emergy analysis for the upper Mekong river intercepted by the Manwan hydropower construction. Renew. Sustain. Energy Rev 51, 899-909.

Guangzhou Municipal Statistics Bureau (GMSB), 2008. Zengcheng Statistical Yearbook. http://data.gzstats.gov.cn/gzStat1/chaxun/njsj.jsp.

Gong, J., Liu, Y., Chen, W., 2012. Land suitability evaluation for development using a matter-element model: a case study in Zengcheng, Guangzhou, China. Land Use Policy 29, 464-472.

Gottmann, J., 1964. Megalopolis: the Urbanized Northeastern Seaboard of the United States. MIT Press, Cambridge, MA, USA.

Guan, L., Zhou, X., Luo, Y., 2005. A review on the study of plant caloric value in China. Chin. J. Ecol. 24, 452-457.

He, G., Yang, J., Lu, Y., Wang, S., Chen, B., Hayat, T., Alsaedi, A., Ahmad, B., 2017. Ternary emergetic environmental performance auditing of a typical industrial park in Beijing. J. Clean. Prod 163, 128-135. http://dx.doi.org/10.1016/ j.jclepro.2015.03.040

Jiang, M., Zhou, J., Chen, B., Chen, G., 2008. Emergy-based ecological account for the Chinese economy in 2004. Commun. Nonlinear Sci. Numer. Simul.13, 2337-2356.
Jiang, M., Zhou, J., Chen, B., Yang, Z., Ji, X., Zhang, L., Chen, G., 2009. Ecological evaluation of Beijing economy based on emergy indices. Commun. Nonlinear Sci. Numer. Simul. 14, 2482-2494.

Kamusoko, C., Aniya, M., Adi, B., Manjoro, M., 2009. Rural sustainability under threat in Zimbabwe-simulation of future land use/cover changes in the Bindura district based on the Markov-cellular automata model. Appl. Geogr. 29, 435-447.

Lei, K., Wang, Z., Ton, S., 2008. Holistic emergy analysis of Macao. Ecol. Eng. 32 $30-43$.

Li, H., Xu, X., Xiao, D., 2007. Study on the value of ecological capital based on the emery theory: A case study on the forest ecosystem in the middle part of the north slope of the Tianshan Mountain. Acta Ecol. Sinica 25, 1383-1390.

Liu, G., Yang, Z., Chen, B., Zhang, L., 2013. Modelling a thermodynamic-based comparative framework for urban sustainability: incorporating economic and ecological losses into emergy analysis. Ecol. Model. 252, 280-287.

Liu, G., Yang, Z., Chen, B., Ulgiati, S., 2014. Emergy-based dynamic mechanisms of urban development, resource consumption and environmental impacts. Ecol. Model. 271, 90-102.

Mellino, S., Buonocore, E., Ulgiati, S., 2015. The worth of land use: a GIS-emergy evaluation of natural and human-made capital. Sci. Total Environ. 506, 137-148.

Millennium Ecosystem Assessment Panel (MEAP), 2005. Ecosystems and human well-being. Island Press Washington, DC, 64P. http://www.who.int/ globalchange/ecosystems/ecosys.pdf.

Molina, M.J., Molina, L.T., 2004. Megacities and atmospheric pollution. J. Air Waste Manag. Assoc. 54, 644-680.

National Development and Reform Commission of China (NDRC), 2014. The new urbanization project. http://www.ndrc.gov.cn/gzdt/201404/t20140418_607923. html.

Nelson, M., Odum, H., Brown, M., Alling, A., 2001. "Living off the land": resource efficiency of wetland wastewater treatment. Adv. Space Res 27, 1547-1556.

Odum, H.T., 1988. Self-organization, transformity, and information. Energy 1, 30

Odum, H.T., 1996. Environmental Accounting: EMERGY and Environmental Decision Making.

Odum, H.T., Brown, M.T., Brandt-Williams, S., 2000. Handbook of Emergy Evaluation-A Compendium of Data for Emergy Computation Issued in a Series of Folios. Folio\# 1: Introduction and Global Budget. Center for Environmental Policy. University of Florida, Gainesville, FL, 16P. http://cep.ees.ufl.edu/emergy/ documents/folios/Folio_01.pdf.

Official Website of Zengcheng Municipality (OWZM), 2015. http://www.zengcheng. gov.cn/publicfiles/business/htmlfiles/zcmh/zjzc/index.html.

Rumbach, A., 2016. Decentralization and small cities: Towards more effective urban disaster governance? Habitat International 52, 35-42.

Sun, M., Yuan, Y., Zhang, J., Wang, R., Wang, Y., 2014. Greenhouse gas emissions estimation and ways to mitigate emissions in the Yellow River Delta Highefficient Eco-economic Zone, China. J. Clean. Prod. 81, 89-102.

Ulgiati, S., Brown, M.T., 1998. Monitoring patterns of sustainability in natural and man-made ecosystems. Ecol. Model. 108, 23-36.

Ulgiati, S., Odum, H., Bastianoni, S., 1994. Emergy use, environmental loading and sustainability an emergy analysis of Italy. Ecol. Model. 73, 215-268.

Vega-Azamar, R.E., Glaus, M., Hausler, R., Oropeza-García, N.A., Romero-López, R. 2013. An emergy analysis for urban environmental sustainability assessment, the Island of Montreal, Canada. Landsc. Urban Plan. 118, 18-28.

Wang, C., Wang, Y., Geng, Y., Wang, R., Zhang, J., 2016. Measuring regional sustainability with an integrated social-economic-natural approach: a case study of the Yellow River Delta region of China. J. Clean. Prod. 114, 189-198.

Zhang, L., Chen, B., Yang, Z., Chen, G., Jiang, M., Liu, G., 2009. Comparison of typical mega cities in China using emergy synthesis. Commun. Nonlinear Sci. Numer Simul. 14, 2827-2836.

Zhang, Y., Yang, Z., Liu, G., Yu, X., 2011. Emergy analysis of the urban metabolism of Beijing. Ecol. Model. 222, 2377-2384.

Zheng, R., Liu, Y., Dong, Y., 2007. Establishment and assessment of early warning system of land safely based on radical basis function model in Guangzhou City. Sci. Geogr. Sin. 27, 778.

Zengcheng Water Supplies Bureau (ZWSB), 2008. Zengcheng Statistical Yearbook. http://tij.zengcheng.gov.cn/.

Zengcheng Planning Bureau (ZPB), 2007. The overall urban development strategic planning of Zengcheng.

Zengcheng Municipal Statistics Bureau (ZMSB), 2008. The Integrated water resources planning report of Zengcheng. 